\title{
La construcción social de los espacios del miedo: Prácticas e imaginarios de las mujeres en Lavapiés (Madrid)
}

\author{
María Patiño-Díe \\ Universidad Nacional de Educación a Distancia. Departamento de Antropología Social \\ y Cultural \\ meriquant@gmail.com
}

\section{Resumen}

Pensar en el miedo en la ciudad teniendo en cuenta el contexto sociocultural nos conduce a observar cómo, en la consideración de ciertas zonas como peligrosas o inseguras, interviene la forma en que las vivencias elaboran el sentido cultural del espacio. Los sentimientos y las percepciones ante los miedos están condicionados por la propia experiencia, que influye en la manera de reaccionar frente a ellos. Por ese motivo, es necesario situar la experiencia femenina en el espacio urbano como punto de arranque de la investigación para estudiar, mediante un análisis de carácter etnográfico, la relación entre ciudad e inseguridad. Este trabajo se ha realizado en Lavapiés, un barrio de Madrid del que el imaginario de una parte de la ciudadanía se ha formado una idea que, muy a menudo, poco tiene que ver con la realidad de lo que allí acontece, lo cual ha contribuido en ocasiones a crear una imagen negativa de un barrio que no todas las mujeres perciben igual.

Palabras clave: inseguridad subjetiva; control social; binomio público-privado; género; espacio urbano. 
Resum. La construcció social dels espais de la por: Pràctiques $i$ imaginaris de les dones a Lavapiés (Madrid)

Pensar en la por a la ciutat tenint en compte el context sociocultural ens condueix a observar com, en la consideració de certes zones com a perilloses o insegures, intervé la manera com les vivències elaboren el sentit cultural de l'espai. Els sentiments i les percepcions davant les pors estan condicionats per la pròpia experiència, que influeix en la manera de reaccionar-hi. Per això, és necessari situar l'experiència femenina en l'espai urbà com a punt de partida de la recerca, per tal d'estudiar, mitjançant una anàlisi de caràcter etnogràfic, la relació entre ciutat i inseguretat. Aquest estudi s'ha realitzat a Lavapiés, un barri de Madrid on l'imaginari d'una part de la ciutadania s'ha format una idea que, molt sovint, té poc a veure amb la realitat del que allà succeeix, amb la qual cosa ha contribuït de vegades a crear una imatge negativa d'un barri que no totes les dones perceben igual.

Paraules clau: inseguretat subjectiva; control social; binomi públic i privat; gènere; espai urbà.

Résumé. La construction sociale des espaces de la peur. Des pratiques et imaginaires des femmes à Lavapiés (Madrid)

Penser à la peur dans la ville en tenant compte du contexte socioculturel nous conduit à observer comment intervient dans la considération de certains espaces comme dangereux ou non sécurisés la forme sous laquelle les expériences élaborent le sens culturel de l'espace. Les sentiments et les perceptions devant les peurs sont conditionnés par la propre expérience, qui influence la manière de réagir en face de celles-ci. Pour cette raison, il est nécessaire de situer l'expérience des femmes dans l'espace urbain comme point de départ de la recherche pour étudier, au moyen d'une analyse de caractère ethnographique, la relation entre une ville et un sentiment d'insécurité. Cette étude a été réalisée à Lavapiés, un quartier de Madrid dont l'imaginaire d'une partie de la citoyenneté s'est formé une idée qui n'a dans bien des occasions pas grand chose à voir avec la réalité de ce qui s'y produit, contribuant ainsi à créer parfois une image négative d'un quartier que toutes les femmes ne perçoivent pas de la même manière.

Mots-clés: insécurité subjective; contrôle social; binôme public-privé; genre; espace urbain.

Abstract. The social construction of spaces of fear: Practices and imaginaries of women in Lavapiés, Madrid

When taking into account the socio-cultural context of fear in the city, it can be observed that certain spaces are considered dangerous or unsafe depending on how our own experiences have shaped our cultural sense of space. Feelings and perceptions of fear are conditioned by our own experience, which in turn influences the way we react to fear. For this reason, it is necessary to situate women's experiences in urban space as a starting point for investigating the relationship between the city and feeling unsafe by means of an ethnographic analysis. This study was carried out in Lavapiés, a neighbourhood in Madrid whose part of the citizenship imaginary has little to do with what is really happening there. A negative image of the neighbourhood has been created which, according to our findings, is not perceived equally by all women.

Keywords: subjective unsafety; social control; public-private binomial; gender; urban space. 


\section{Sumario}

1. Introducción 5. Conclusiones

2. Metodología Referencias bibliográficas

3. Apuntes sobre Lavapiés

Anexos

4. La «cultura del miedo»

\section{Introducción ${ }^{1}$}

El objetivo de este artículo es indagar acerca de cómo espacio, lugar y género están interconectados y cómo esta construcción social y subjetiva influye en la experiencia de la ciudad por parte de las mujeres. Aunque los miedos en la ciudad han sido ampliamente tratados, el hecho de centrar el análisis en Lavapiés, un barrio con una gran complejidad sociocultural, es interesante a la hora de estudiar de qué modo las mujeres pueden percibir la ciudad como un lugar inseguro y peligroso, así como de qué modo las políticas públicas y el urbanismo intervienen en dicha percepción. Así, la constante presencia policial, la decisión del Ayuntamiento de Madrid de colocar cámaras de videovigilancia ${ }^{2}$ y el tratamiento que los medios de comunicación realizan de algunos sucesos han contribuido a crear una imagen del barrio como lugar peligroso, lo cual ha desempeñado un papel decisivo en la inseguridad subjetiva, en la diferente apreciación que tienen las y los habitantes de una misma ciudad sobre la seguridad de su entorno.

La experiencia del miedo existente y la realidad de los imaginarios del miedo se ha puesto en relación con el derecho a la autonomía y a la libertad de movimiento de las mujeres, que ponen en juego diferentes estrategias para conquistar la ciudad, tal y como nos muestran las que fueron entrevistadas en Lavapiés, donde los imaginarios y lo real se entrecruzan en una visión en ocasiones deformada de la realidad. Mientras unas personas idealizan el barrio con la seducción de la multiculturalidad, lo popular, otras ven problemas, delincuencia e inseguridad.

La construcción del espacio en lugares «seguros» y «peligrosos» no es algo fútil, puesto que los espacios forman parte de la experiencia cotidiana y «encierran contenidos poderosos para la interpretación social y cultural» (Del Valle, 1997: 25). El miedo se ha puesto en relación con la seguridad, sin embargo, no todo lo que se lleva a cabo para ofrecerla evita el miedo a las personas. En la

1. El artículo que aquí se muestra es parte de un estudio más amplio realizado para el trabajo final de investigación del Màster en Estudis de Dones, Gènere i Ciutadania, con el título Los espacios del miedo: espacios físicos y simbólicos. Estudio de caso: Lavapiés (Madrid), presentado en la Universitat de Barcelona el dia 27 de junio de 2013.

2. En 2009 , se instalaron en Lavapiés 48 cámaras de videovigilancia. Con motivo de su colocación, se montó la plataforma ciudadana Un Barrio Feliz, que organizó numerosas acciones en contra de lo que consideraban un elemento de control injustificado para garantizar la seguridad en el barrio (<http://unbarriofeliz.wordpress.com>). 
actualidad, el modelo hegemónico, que concibe la seguridad contra la propia libertad, rescinde los movimientos de las personas, pero seguridad y libertad no tienen por qué ser modelos antagónicos. Hablar de inseguridad, tanto objetiva como subjetiva, nos conduce a poner el foco en la construcción de los espacios públicos como lugares inseguros para las mujeres y de los privados como lugares de refugio, cuando la realidad es que el mayor número de agresiones que sufren las mujeres se producen en los espacios privados, en lo doméstico.

Analizar los espacios del miedo de las mujeres lleva a plantearse si sus actitudes, sus percepciones o proyecciones son iguales para todas, si existe mujer (o mujeres) como categoría de análisis, puesto que no constituyen un colectivo homogéneo: la clase, la edad, la religión, la sexualidad y el grupo étnico establecen diferencias entre ellas. Estas variables influyen en la construcción de las percepciones individuales y en las experiencias de los espacios cotidianos. Hay que descartar, por tanto, que las mujeres sean un grupo de investigación per se y preguntarse qué es lo que hace de un grupo de mujeres una categoría susceptible de ser investigada (McDowell, 2000). Señalar una problemática específica no se refiere a características biológicas o sociales fijas, sino a un conjunto de situaciones surgidas a partir de la asignación a las mujeres de una identidad diferenciada como resultado de una visión androcéntrica, cuestionada desde el feminismo, ya que implica jerarquía y trato inferior.

Es importante remarcar la capacidad del espacio para diferenciar y jerarquizar socialmente. Subrayar la segregación espacial y su relación con la segregación social en función del género es fundamental, ya que «los espacios que ocupan las mujeres o aquellos que les están vedados tienen mucho que ver con un determinado orden social» (Del Valle, 1997: 35), con la producción común del espacio y con las regulaciones que influyen en quien ocupa un lugar determinado y quien queda excluida de él. Se trata de examinar hasta qué punto las mujeres y los hombres experimentan los lugares de distinto modo y mostrar que tales diferencias forman parte tanto de la constitución social del lugar como del género. El lugar se hace material a través de la ocupación y el uso del espacio como producto de las relaciones sociales y de las negociaciones de poder. Así, la segregación de espacios y la asignación diferenciada de mujeres y hombres a los mismos ha llevado a una construcción sociocultural de los roles de género que ha configurado hasta la actualidad la creencia de que, cuando ellas se encuentran en el espacio público, no lo hacen como si fuera este un espacio al que tienen derecho, porque no es el que les corresponde, lo cual ha conformado ciertas prácticas e imaginarios de las mujeres en la ciudad ${ }^{3}$.

El binomio público-privado muestra una valoración diferencial para mujeres y para hombres en el espacio público, donde se produce ciudadanía. La diferen-

3. En la época industrial, se creó un mundo jerarquizado por el género que marcó la trayectoria de vida de las mujeres y su cometido social. Un sistema de género basado en un discurso de la domesticidad que confinaba a las mujeres en la casa y les atribuía la única identidad de madres y esposas (Nash, 2007) y que tuvo una gran implicación en la construcción sociocultural sobre el derecho femenino a estar en la urbe, así como en la interiorización por parte de estas de ciertos patrones de conducta. 
cia sexual que organiza la sociedad también ha estructurado las ciudades, donde los dos sexos no tienen el mismo derecho al uso del espacio urbano, con lo cual se produce una sexualización de este frente a la pretendida neutralidad del mismo. Las configuraciones espaciales, trazadas desde las estructuras de poder e influenciadas por una visión masculina de la sociedad, se han conformado remitiendo a la mujer a ocupar ciertos lugares. A las mujeres se las ha excluido y se las continúa excluyendo. Su percepción como seres frágiles, como el considerar que deberían estar en casa por su propia protección, reduce su derecho a la libertad ${ }^{4}$. Es en el espacio donde se reproducen las ideologías hegemónicas, donde la experiencia cotidiana cobra sentido, además de desempeñar un importante papel en la reproducción de las estructuras patriarcales y en las ideologías e imaginarios sobre el miedo. Es necesario, por tanto, cuestionar la construcción que, desde la modernidad, determina la asignación y la vinculación de las mujeres con el mundo privado-doméstico, que se asocia con su ausencia en los lugares de representación. El feminismo proporciona herramientas de análisis para convertir a las mujeres en sujetos políticos. Esto implica una redefinición de lo político que introduce lo personal y lo privado en su misma constitución, rompiendo la dicotomía entre lo privado y lo público.

\section{Metodología}

Los datos en los que se basa el análisis de este artículo se han obtenido mediante una metodología cualitativa basada principalmente en entrevistas y en un grupo de discusión con mujeres que viven en Lavapiés y aquellas que lo frecuentan como lugar de ocio o de trabajo. De estos materiales están extraídas las citas introducidas en el texto.

En relación con un análisis del espacio y su ocupación, se planteó el desarrollo de una observación participante en un contexto de interacción desde el que observar y registrar aspectos que ayudaran a los objetivos de la investigación. Posteriormente, se realizaron entrevistas semiestructuradas frente a otras más estructuradas para permitir la aparición de un mayor contenido temático. En las entrevistas, no se marcó una duración determinada, el tiempo osciló entre cuarenta minutos y una hora, dependiendo de la disposición de las participantes. El lugar fue elegido por las mujeres, generalmente en espacios públicos (plazas, calles, parque del Casino de la Reina) o semipúblicos (bares, la terraza de la UNED). Las entrevistas que no habían sido programadas pre-

4. El modelo de dominación masculina sobre la mujer se ha desarrollado en el ámbito familiar y del Estado. La distinción entre público y privado establecía que lo primero debía constituirse en un territorio homogéneo y tranquilo sometido a la vigilancia del Estado, mientras que lo segundo se hallaba sometido a la vigilancia de los hombres — padres, esposos, hermanos-. El tránsito de las mujeres por los espacios públicos siempre se ha visto con prevención por parte de los sectores hegemónicos de la sociedad, porque contravenía el arquetipo femenino de la domesticidad, y también de los hombres de las clases sociales con menos recursos, trabajadores y sindicatos, porque valoraban el trabajo remunerado de las mujeres como «competencia desleal» (Segura, 2006). 
viamente se desarrollaron en la calle o en locales en los que trabajan ellas (con algunas fue posible concertar otro encuentro más estructurado tras ese primero). La mayoría de las mujeres con las que se habló sin cita previa eligieron no ser grabadas. Las entrevistas concertadas sí se grabaron.

Se entrevistó a 30 mujeres, sin buscar un perfil específico 5 . Puesto que las diferencias sociales producen percepciones distintas en relación con el miedo y con la interpretación de los espacios, que no son exclusivas de las mujeres ni idénticas entre ellas, se intentó que la muestra reflejara las voces de mujeres de distintas edades y procedencias (en el caso de las de otros países, la selección de las informantes se basó en su conocimiento del castellano, de otro modo no hubiera sido posible establecer una comunicación en la que no se produjeran malentendidos entre informante e investigadora). La investigación está limitada en el tamaño de la muestra, por lo que no se pueden generalizar posiciones específicas, pero sí mostrar un reflejo — parcial— de la sociedad a través de la voz de sus protagonistas.

El grupo de discusión, con el que se mantuvo dos encuentros, formado por 5 o 6 mujeres de entre 30 y 52 años con participación activa en organizaciones del barrio, como La Tabacalera ${ }^{6}$, permitió conocer las opiniones individuales, además de llevar a cabo una reflexión colectiva. En la primera sesión, se intervino lo imprescindible, mientras que, en la segunda, se hicieron una serie de preguntas más concretas sobre aspectos de interés para la investigación que no habían surgido anteriormente. Tras la primera sesión, se les solicitó que se fijaran en los puntos que consideraban problemáticos para situarlos en un plano y hacer una descripción más detallada de estos en el segundo encuentro ${ }^{7}$.

Aunque, en un principio, se optó por explicar el objeto de la investigación (los espacios del miedo y su implicación en la vida diaria de las mujeres para ejercer una ciudadanía autónoma), tras varias semanas de trabajo de campo, el acercamiento hacia algunas mujeres con las que se habló sin haber establecido un contacto previo se modificó para que no se generara un clima de desconfianza y prevención. Así, lo que se pidió fue su colaboración para señalar topográficamente los lugares que percibían como inseguros dentro del barrio, lo que facilitó ir ampliando la temática hacia las causas y las consecuencias de dicha inseguridad, así como las estrategias de cada una para afrontar los miedos o las inseguridades.

Se han tratado primordialmente tres aspectos. Uno referido al espacio físico, mediante la localización y la descripción de puntos oscuros en Lavapiés. Otro al espacio simbólico, con relación a cómo influyen el imaginario anticipatorio y las experiencias en la percepción del espacio público. Y, por último, las herramientas para afrontar el temor, mediante el empoderamiento, la autonomía y la búsqueda de libertad al moverse por la ciudad. Mientras que con

5. Sobre el perfil de las participantes, véase las tablas 1 y 2 del anexo.

6. Centro social autogestionado situado en la antigua Fábrica de tabacos de Lavapiés.

7. Los planos sobre los que se trabajó provienen del Área de Gobierno de Urbanismo y Vivienda del Ayuntamiento de Madrid, del Servicio de Cartografía e Información Urbanística. Dirección General de Planeamiento. 


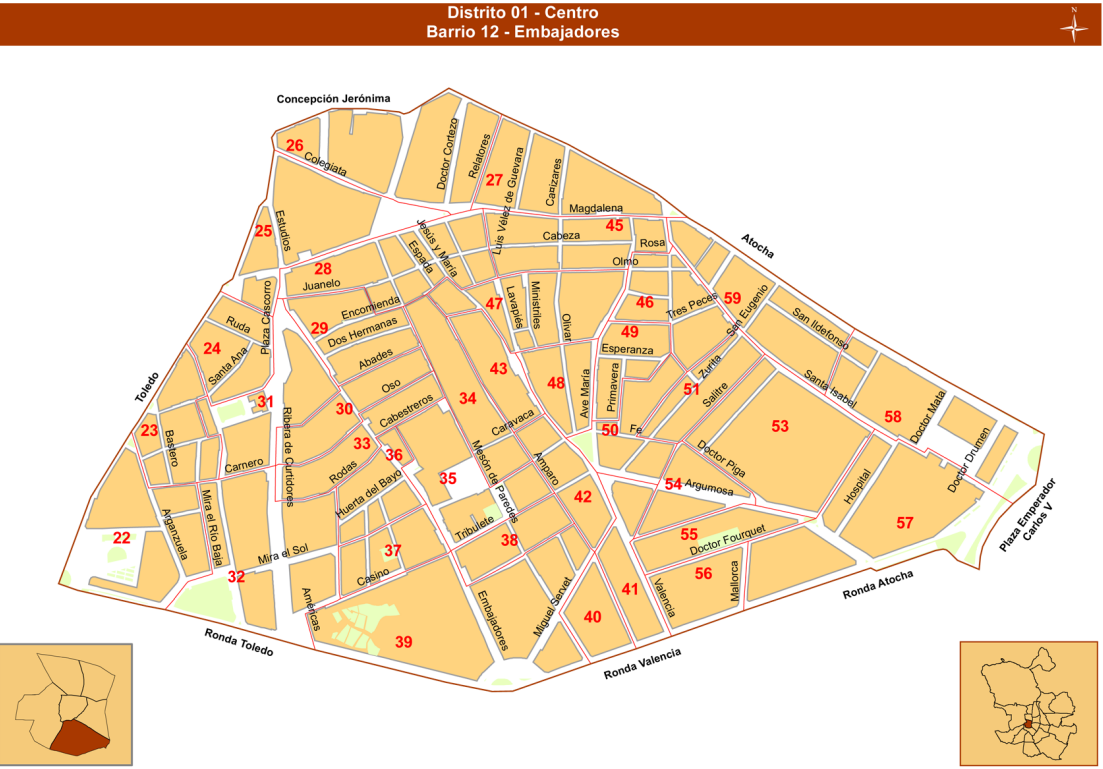

Figura 1. Barrio de Embajadores-Lavapiés.

Fuente: Dirección General de Estadística del Ayuntamiento de Madrid.

algunas mujeres se profundizó en estos tres aspectos, con otras únicamente se señalaron los lugares que les infundían temor, sin reflexionar sobre las causas o sus propias iniciativas a la hora de transitar por el espacio urbano, de estar en él.

Se ha puesto gran cuidado en llevar a cabo el estudio con ética, empatía e imparcialidad, dándose especial énfasis al consentimiento informado, al derecho a retirarse, a la confidencialidad y al anonimato. El propósito de la investigación se ha explicado a las participantes al inicio de las conversaciones, para conseguir su colaboración.

\section{Apuntes sobre Lavapiés}

Lavapiés se caracteriza en el imaginario popular como uno de los barrios más castizos de $\mathrm{Madrid}^{8}$. Próximo a la puerta del Sol y a la plaza Mayor, le circunscriben las rondas de Atocha y de Valencia al sur, la calle de Ribera de Curtidores al oeste, la plaza de Tirso de Molina al norte y la calle de Santa Isabel al este.

A principios de la década de 1990, fue considerada una de las áreas más deterioradas del centro, situación que se ha intentado solventar a partir de su

8. Aunque Lavapiés se denomina popularmente barrio, en realidad, pertenece al barrio de Embajadores, integrado en el distrito Centro. Véase los planos del anexo. 
declaración como Área de Rehabilitación Integral (ARI-Lavapiés) en 1999, con una inversión por parte de la Administración destinada a rehabilitar el barrio y a terminar con su condición de espacio inseguro (Cañedo, 2011) 9 .

Aunque no se puede decir que sea un barrio aislado y marginado como lo fue en otras épocas —actualmente es un espacio de ocio importante-, sigue teniendo una imagen negativa para algunas personas debido a la inmigración y a la gentrificación ${ }^{10}$. Esta imagen aparece en numerosas ocasiones alimentada por los medios de comunicación, la instalación de cámaras de videovigilancia ${ }^{11}$ y el aumento de efectivos policiales en la zona ${ }^{12}$, medidas que han reforzado la idea de lugar peligroso e inseguro.

Uno de los rasgos que caracteriza a Lavapiés es su heterogeneidad y complejidad sociocultural, lo que, en ocasiones, dificulta la convivencia vecinal. Unas cuarenta mil personas - un tercio de ellas son inmigrantes de diferentes nacionalidades - se encuentran y chocan en este "pueblo en medio de la capital» (tabla 1).

Normalmente, este barrio es totalmente un pueblito, y lo que suele pasar normalmente es que conoces a la señora María que vive enfrente y es una señora mayor que va a la compra como en cualquier sitio, lo que pasa es que ella está conviviendo con todo tipo de razas y todo tipo de estatus sociales, ¿no?, porque yo conozco gente de pasta que vive aquí, gente que tiene un estatus social un poco más bajo, económicamente tiene menos poder adquisitivo pero que se convive. Hay mucho tipo de convivencia, no solo racial, ¿no?, sino que económica y de nivel cultural [...] eso le enriquece un montonazo a este sitio. (Е., 52 años)

La inmigración es señalada como uno de los principales problemas del barrio. Inmigración que no ha sido únicamente extranjera y que ha ido transformando su composición demográfica. Las vecinas y los vecinos de toda la vida llegaron tras la Guerra Civil española o en los años sesenta y setenta desde las zonas rurales, en paralelo a la industrialización de Madrid. La crisis económica de los años setenta, junto con la urbanización de las periferias, provocó un estancamiento en la llegada de nuevas migraciones y una salida de quienes residían en el barrio — sobre todo de jóvenes - hacia nuevas viviendas en zonas más alejadas del centro. Esto dio lugar a un despoblamiento y a un envejecimiento progresivos de la población, así como a una degradación del espacio en los años ochenta. Desde los noventa, comenzaron a llegar inmigrantes de

9. Según datos de la policía municipal en el momento en que esta investigación se llevó a cabo, en Lavapiés, la tasa de criminalidad estaba por debajo de la media del distrito.

10. Diferentes estudios geográficos proponen el término elitización fente al neologismo gentrificación.

11. Para consultar la localización de las cámaras, mirar el plano que consta en el anexo.

12. Desde el 1 de julio de 2012, Lavapiés cuenta, dentro del Plan Integral de Mejora de la Seguridad y la Convivencia elaborado por la Delegación del Gobierno, con un dispositivo especial de seguridad que supone más policías en la calle (<http://www.elmundo.es/elmundo/2012/06/27/madrid/1340804454.html>). 
Tabla 1. Características generales referentes a los orígenes de las personas que viven en el barrio de Embajadores, distrito Centro (revisado a 1 de enero de 2013)*

\begin{tabular}{lrrr}
\hline Población según nacionalidad & Ambos sexos & Hombres & Mujeres \\
\hline Total & 47.470 & 24.475 & 22.995 \\
Española & 33.911 & 16.251 & 17.660 \\
Extranjera & 13.559 & 8.224 & 5.335 \\
Unión Europea (15) & 2.560 & 1.341 & 1.219 \\
Unión Europea (ampliación a 27) & 747 & 317 & 430 \\
Otros países OCDE & 596 & 281 & 315 \\
Otros países de Europa & 181 & 60 & 121 \\
América Latina y Caribe & 3.304 & 1.617 & 1.687 \\
África & 1.868 & 1.325 & 543 \\
Asia y Oceanía & 4.298 & 3.278 & 1.020 \\
Apátridas & 5 & 5 & 0 \\
No consta & 0 & 0 & 0 \\
Porcentaje de extranjeros & 28,6 & 33,6 & 23,2 \\
\hline
\end{tabular}

Fuente: Padrón municipal del ayuntamiento de Madrid. Área de Gobierno de Hacienda y Administración Pública. Dirección General de Estadística.

* Según los datos padronales, basados en los diez países con un mayor número de residentes inscritos en la ciudad de Madrid en 2013, en Embajadores vivían 795 personas originarias de Ecuador, 441 de Rumanía, 268 de Perú, 347 de Bolivia, 732 de China, 333 de Colombia, 980 de Marruecos, 271 de República Dominicana y 9.392 de otros países. (Fuente: Ayuntamiento de Madrid. Área de Gobierno de Hacienda y Administración Pública. Dirección General de Estadística. Explotación Estadística del Padrón Municipal de Habitantes.)

origen extranjero y gente joven, atraídos por su centralidad y por los precios de la vivienda. Fue en estos años cuando se instalaron en Lavapiés personas progresistas en lo político y en lo social, así como activistas asociados a la Red de Colectivos de Lavapiés ${ }^{13}$, que llevan años intentando hacer del barrio un laboratorio de ciudadanía participativa.

\section{La «cultura del miedo»}

La ciudad significa temores, placeres, peligros y libertades distintos para mujeres y hombres. Una percepción diferencial que se extiende a la sensación de (in) seguridad y miedo, con referentes y significados distintos para ambos (Falú, 2009; Rainero, 2009; Román, 2009; Del Valle, 2006). Estos miedos, que se relacionan con las construcciones históricas y culturales de «ser mujer», contribuyen en numerosas ocasiones a debilitar su autoestima y acrecientan los sentimientos de inseguridad.

13. Esta red fue formada en 1997 por asociaciones culturales, colectivos de inmigración, okupas y cooperativas sociales. Se crearon varias comisiones para analizar la realidad del barrio con la intención de fortalecer su tejido social. Demandaban respuestas a carencias y a problemas existentes en él planteando propuestas, al tiempo que se quería fomentar la participación de las vecinas y de los vecinos acerca de lo que ocurría o querían que ocurriera en Lavapiés. 
La percepción de inseguridad tiene mucho que ver con la socialización. La sociedad patriarcal ha educado a las mujeres para estar alerta frente a peligros difusos, y la violencia hacia ellas encuentra explicaciones causales en su propia conducta. Los comportamientos esperados de estas en la ciudad hacen que surjan afirmaciones como: «Las mujeres deben evitar vestirse provocativamente para no ser molestadas en la calle», "No deben transitar ni permanecer solas en los espacios públicos para evitar riesgos». Desde pequeñas entran en el espacio urbano con la advertencia de que su seguridad depende en gran medida de su comportamiento, han interiorizado el peligro y han aprendido que su proceder es determinante a la hora de librarse de él. Esas medidas que asumen como mujeres tienen un gran coste para su libertad de tránsito por la ciudad, su confianza en sí mismas y sus capacidades, así como la confianza en personas desconocidas. El miedo, que se inculca desde la infancia con mensajes como «No te fíes de desconocidos», puede coartar el acceso libre de mujeres y niñas al espacio público. Inhibición que no pesa como una prohibición expresa, sino que se termina asumiendo como una renuncia personal, ocultándose su carácter colectivo y, con ello, la capacidad de intervenir en esa esfera. Funciona desde aquel discurso que considera que la asociación mujer-calle hace referencia a aquellas que están fuera del lugar o del momento que les compete (Román, 2009). ¿Pasamos miedo porque hemos asumido que estamos en un lugar que no nos corresponde?

El miedo en la ciudad no es un fenómeno exclusivo de nuestra época. En cada momento histórico, los miedos ciudadanos reflejan lo concreto de la situación social y urbana. Por ello, es importante poner en evidencia la especificidad de los sentidos particulares que la inseguridad tiene en cada espacio social determinado. Así, cuando se les pregunta a las vecinas sobre el barrio de Lavapiés, trabajan con el lenguaje para representarlo. Un lenguaje que nombra calles que remiten a sucesos, a trayectos placenteros o que producen temores. Lo que están realizando es una construcción simbólica del barrio, no expresando únicamente una presencia física sobre él.

Las fuentes de inseguridad de las mujeres que han participado en este estudio son diversas, en ocasiones resulta difícil encontrar las raíces de los propios miedos. Pero, a pesar de la heterogeneidad de experiencias y la diversidad de posiciones dentro de la sociedad, la violencia, en sus diferentes caras, es uno de los temores que más comparten. La percepción del miedo, la sensación de amenaza y los comportamientos espaciales que desarrollan dependen de la edad, de las capacidades o de su condición de inmigrante. Aún así, las mujeres viven el temor independientemente de sus diferentes identidades sociales. El miedo precede o acompaña a las violencias (Falú, 2009).

En sus discursos, algunas mujeres reflexionan sobre qué les produce miedo o inseguridad al transitar por el barrio, qué o quiénes les hacen sentir temerosas o inseguras, otras, en cambio, se basan en noticias que aparecen en los medios de comunicación, en la presencia policial, en sucesos que les han contado o que han sufrido ellas mismas. En ambos casos, tanto los imaginarios como la realidad desempeñan un papel importante. Algunas han desarrollado una conciencia crítica sobre factores estructurales y culturales que determinan la 
manera de vivir en la ciudad, otras tienen ideas preconcebidas sobre lo que genera miedo. Al preguntarles qué personas les parecen atemorizantes, siempre hacen referencia a los hombres ${ }^{14}$. El referente de inseguridad de la mujer siempre es un hombre. En el fondo, subyace el miedo a una agresión física, aunque no siempre se verbaliza. Muchas consideran que la posibilidad de sufrir una agresión viene determinada por la capacidad de los hombres de imponerse físicamente. No han reflexionado sobre si esta superioridad tiene que ver con aspectos psicológicos, sociales, estructurales, que convierten a los hombres en «agresores potenciales» debido a una diferencia en las relaciones de poder entre mujeres y hombres.

No te puedes defender cuando una persona, un hombre, es más fuerte físicamente que tú [...] Ver si estás dispuesta a entrar en una «batalla», a dar una respuesta en la que tú te repongas, te impongas, es importante a la hora de ser consciente de la actitud con la que accedes al espacio público. (L., 33 años)

Yo creo que no solo es superioridad física, sino también, como tú eres mujer, por desprecio, ¿no? [...] Los rangos de poder, yo creo que es un poco eso. [...] Físicamente, un hombre tiene más poder que una mujer, entonces siempre el hombre por encima, en cuestiones de agresión, de lo físico. (P., 47 años)

También tienes algo más. Tienes algo más también para, porque te pueden atracar, te pueden, te pueden pegar, te pueden violar, pueden abusar de ti. No sé, es, tienes más que perder. Y eres más vulnerable, no sé. [...] eres más vulnerable. (I., 39 años)

Físicamente, eres más vulnerable. [...] yo creo que si atacan a una mujer antes que a un hombre es porque saben que físicamente pueden con ella. [...] yo la agresión la identifico con hombres, y fuerza física. (R., 39 años)

\subsection{Inseguridad real y subjetiva}

Las drogas, el gamberrismo, la violencia y sobre todo los robos son frecuentemente aludidos por algunas mujeres a partir de casos personales o de personas conocidas del entorno, una sensación de inseguridad que limita su movilidad y su presencia en algunas zonas del barrio, principalmente al anochecer. Las peleas entre hombres - por asuntos relacionados con drogas o porque han bebido demasiado - también causan temor, lo que declaran es la prevención de no encontrarse en medio de una reyerta. Existe la idea de que la vida en el barrio era más segura hace años, aunque, al mismo tiempo, recuerdan que «había mucha droga, con yonkies por las aceras». La delincuencia relacionada con las drogas, sobre todo la idea de peligrosidad que conlleva, se ha trasvasado de los autóctonos a los inmigrantes.

14. Solo dos mujeres aludieron a un episodio violento proveniente de otra mujer: un atraco y una agresión en el antiguo Medea (bar de lesbianas), hoy Club 33. 
En otros casos, la inseguridad no se manifiesta en la agresión a personas o en el robo de sus bienes, sino en la destrucción del mobiliario urbano y del espacio público en general, en el desorden y la suciedad. La crítica fundamental se relaciona con una falta de respeto a las normas de convivencia.

¿Qué tipo de experiencia de lo urbano aparece para las mujeres y qué sentido se traduce de estas experiencias? Para expresar y ordenar su experiencia particular, se apropian de escenas, de argumentos que circulan dentro de la consideración social de aquello que provoca inseguridad. La inseguridad o «cultura del miedo» (Machado, 2009) es tratada como una reacción directa a actos de agresión efectivamente practicados; sin embargo, también es socialmente construida a partir de un imaginario simbólico, asociándola a lugares señalados como peligrosos, como es el caso de Lavapiés. Hablar sobre las amenazas reales y los temores imaginarios nos lleva a pensar que estos, si bien se fundan en hechos concretos, también se construyen sobre el imaginario y son interpretados y reinterpretados por la ciudadanía, en una percepción en la cual los medios de comunicación desempeñan un importante papel. Cómo se comunica y qué se comunica puede contribuir a la estigmatización de un barrio, a mostrarlo como atemorizante. Las reacciones «naturales» en respuesta a aquellas amenazas que producen temores son no salir, no exponerse. Pero, en la mayoría de las ocasiones, las formas de autoprotección, lejos de generar seguridad, la detraen (Adams, 1999). Algunos de los mecanismos de autoprotección que se están implantando para luchar contra la inseguridad no hacen más que alimentarla.

Definir la inseguridad como sinónimo de criminalidad callejera, además de presentar la sensación de inseguridad como única cuando es una experiencia múltiple y diversa, deja fuera otras dimensiones del problema, evita el cuestionamiento de las relaciones de poder —económicas, políticas, de género- que la provocan y justifica una política cada vez más represora frente a ciertos grupos, al tiempo que legitima la restricción de libertades y derechos ciudadanos en nombre de una lucha contra la delincuencia.

Lavapiés es un ejemplo de cómo, a mayor percepción de inseguridad, más represión, y a mayor represión, más sensación de inseguridad. Así, varias mujeres comentaban que «el barrio está cada vez más inseguro, porque si hay tanta presencia policial, por algo será», idea que aparece también en los testimonios de quienes no viven allí, mediatizada por la imagen que se da del barrio.

[...] de pronto lo externo informa de que este barrio, en este barrio pasan muchas cosas, muchos peligros que tú ¿sabes?, eres un pendejillo por la calle y te puede pasar cualquier cosa. $Y$ eso es verdad que se crea totalmente. $\mathrm{O}$ sea a nivel turístico, a nivel de coger taxis. Ahora, no tanto ¡eh!, pero yo me acuerdo de muchos taxistas no querer entrar en el barrio, de «Ah, no, no, yo te dejaré abajo» [...] Pero yo creo que sí, que es una serie de informaciones las que nos llegan que son muy muy nocivas [...] Y en ese sentido creo que uno se autosugestiona con estas informaciones que parecen venir de una fuente verdadera. (E., 52 años) 
Situar la experiencia de las mujeres en Lavapiés nos lleva a observar cómo lo que para algunas de ellas aporta un razonamiento positivo a la hora de pensar que la inseguridad es real y que, por tanto, es necesaria esta "protección", para otras representa un recorte a sus libertades. La presencia de policías y de cámaras de videovigilancia es interpretada de diferentes maneras según la edad, el activismo político o la situación de «irregularidad». Mientras unas la consideran un síntoma de lo peligroso que se ha vuelto el barrio, por lo que ver a las patrullas o conocer la disposición de las cámaras les induce seguridad, para otras es la expresión de una sociedad de control y un atentado contra su intimidad. La percepción acerca de los mecanismos de protección en la ciudad y de lugares considerados de mayor o menor riesgo no es la misma para todas las mujeres: donde unas encuentran protección - la relación con las instituciones-, otras perciben una amenaza (esto ocurre también en Lavapiés entre ciertos grupos críticos con el sistema, inmigrantes en situación de «irregularidad», okupas, etc.).

A mí, las cámaras no me dan ninguna seguridad, porque creo que están para vigilarme a mí [...] creo que es una sociedad de control, más que de protección, creo que les importa un huevo mi protección [...] Lo de la protección es, ¿quién vigila al vigilante? Esa es la pregunta. (V., 40 años)

Es que no veo la seguridad por ningún lado, al menos para mí, para mi gente [mujer marroquí]. Bajas a comprar y no puedes volver a casa porque está la policía en la plaza [de Lavapiés] y sabes que te van a, a pedir la documentación. (A., 29 años $)^{15}$

Pero este sentimiento de inseguridad y la idea de barrio peligroso no aparece en todas las mujeres. Algunas manifiestan que tienen la confianza de que, si algo les sucediera, precisamente por estar en el barrio, serían ayudadas.

A mí, a mí este barrio no me da ningún miedo, ahí para empezar. O sea, me parece uno de los pocos espacios en la ciudad donde de pronto uno puede ser como es y uno puede expresarse como se exprese [...] este barrio yo creo que es como un espacio de libertad. Lo que pasa es que, claro, eso no deja de ser una cosa utópica, hablar y que, que bueno está un poco interferida por algunas realidades que de pronto sí que se dan y que son perfectamente visibles. (E., 52 años)

Fíjate, a mí me pasa, ya conociendo y porque vivo aquí, que también por el tipo de gente, yo confío más en que me puedan ayudar aquí si me atraca alguien, que alguien que pase por la calle me eche una mano, que si fuese en el barrio de Salamanca [...] Y eso a mí sí me da un poco más de seguridad. (P., 47 años)

En la ciudad actual, se dan fenómenos de apropiación de áreas históricas y barrios tradicionales por parte de poblaciones inmigradas, así como procesos

15. La mayoría de arrestos se deben a la ley de extranjería (LO 4/2000). 
de gentrificación. Ambos procesos han ocurrido en Lavapiés desde los años noventa. La presencia de colectivos con imagen de peligrosidad, de inmigrantes no comunitarios en el caso de Lavapiés, es suficiente para que una parte de la opinión pública sobrevalore el grado de inseguridad real. En la ciudad, se teme a "los otros", "la excesiva homogeneidad es insípida, pero la diferencia inquieta» (Borja, 2003: 202).

La construcción social de los discursos del miedo puede ser utilizada con fines políticos: las iniciativas de seguridad multiplican la información, se hacen campañas, aumenta la inseguridad subjetiva ${ }^{16}$. Así, el miedo en la imaginación, la evitación de espacios percibidos como peligrosos en ciertos momentos y su asociación con los extranjeros están sustentados en muchos casos en temores basados en estereotipos. Sin embargo, el miedo tiene efectos tangibles en la interacción social, en la utilización del espacio y en la calidad de vida, especialmente entre quienes experimentan algún nivel de exclusión social o marginación de ciertos espacios (Pain, 2001). En Lavapiés, el inmigrante es una figura recurrente en los discursos sobre inseguridad. Se vincula inmigración e inseguridad principalmente a partir de la categorización de la persona foránea como «ilegal» y se asocia con actos delictivos como robos, atracos y trapicheo. Esta asociación de actos delictivos y de agresiones con hombres inmigrantes varía según los testimonios: mientras algunas mujeres dicen sentir temor frente a los magrebíes, otras señalan a los subsaharianos, pero en ningún caso se apunta a los bangladesíes, a los pakistaníes, a los chinos o a los latinos, muy numerosos en el barrio. Algunas afirman que lo que les despierta recelo es el desconocimiento de ciertos códigos de conducta y culturales. No controlan el contexto y eso les provoca inseguridad y miedo. La percepción del otro como agresor potencial no corresponde siempre a una realidad objetiva. El temor se produce en ocasiones por comportamientos que, para unas personas, son agresivos y, para otras, expresivos («Los subsaharianos gritan mucho, parece que están peleando»), y que coinciden con diferencias culturales (Borja, 2003).

¿Qué es lo que subyace a la señalización de los inmigrantes — no comunitarios - como culpables de la decadencia del barrio? Una comunidad no es un todo homogéneo, sino un espacio de conflicto. En numerosas ocasiones, no existe una convivencia ciudadana, sino una situación de copresencia. Pocas mujeres que manifiestan sentir temor ante hombres inmigrantes han mantenido alguna relación con ellos. Se basan en lo que han oído contar, en robos, en asaltos que parecen ocurrir en todos lados y en todo momento. La inseguridad subjetiva deriva de la pérdida de las relaciones de vecindad, de los obstáculos ante una convivencia intercultural bajo condiciones en ocasiones precarias y también de episodios reales de delitos que ocurren. Los miedos tienen una

16. Un ejemplo fue el tratamiento mediático que se dio en el año 2000 a la «banda del pegamento", un grupo de menores de origen magrebí que perpetraba robos con violencia. A raíz de este problema, los medios de comunicación, alentados por las instituciones y algunas asociaciones de la zona, crearon una psicosis colectiva que sirvió para justificar la toma del barrio por parte de la policía. 
base real —es cierto y así lo evidencian los testimonios de algunas mujeres que han sido agredidas, que los problemas están, y cuanto más complejo es un vecindario, más problemas de relación tiene-, pero la virtualidad empieza cuando los medios de comunicación o determinadas políticas nos hacen ver a ciertos grupos como delincuentes potenciales. Se los considera personas que "no quieren trabajar», a quienes se "regala la vivienda», que "no respetan ni quieren integrarse» y se les relaciona directamente con el aumento de la criminalidad. En general, en los testimonios de las mujeres, no se llegan a analizar factores estructurales como la precariedad y la ausencia de oportunidades para quienes han venido buscando una vida mejor y más digna, aunque alguna de las ellas sí reflexionaba sobre dicha cuestión:

De pronto visualizas cómo hay gentes que llegan con una expectativa y de pronto están en una situación de la que no pueden salir, porque ni, ni han encontrado trabajo, ni, ni nada. Un tío buenísimo [un subsahariano que iba al bar donde trabaja], porque yo le he visto vivir en la calle [...] Te lo juro que, para mí, es la vergüenza, el momento de « ¡Hostia! ¡iCómo podemos saber que esto existe y cómo no podemos hacer nada!?» [...] una impotencia, una situación que de pronto no puedes agarrar por ningún lado, por ningún lao y, ¡hostia!, a mí eso me parece de las cosas más duras que pasan aquí, ¿sabes?, porque, bueno, ese tío era un tío culto, con estudios y de pronto no es un tío que de pronto vaya a ni a robarte ni a..., es que para nada. Lo que quería era sobrevivir, pero, eso es una minoría, el resto puede que de pronto te encuentres en una situación como esta y vienes [al bar], robas tres bolsos o atracas en la calle, ¿sabes?, que, pero todo esto es una consecuencia de, de las situaciones. Lo que pasa es que, claro, no es para justificarlo, como decíamos antes, ¿no? (Е., 52 años)

\subsection{Espacios de riesgo y de conflicto}

El espacio público no es solo de refugio o de violencia, también puede serlo para la transgresión, el riesgo, la resistencia. Esta dimensión de riesgo y conflicto es fundamental para la construcción de un espacio público donde exista una ciudadanía activa y donde la construcción de la seguridad vaya asociada a asumir riesgos, no a evitarlos. «El problema no está en que los espacios sean de riesgo o conflictivos, sino en cómo nosotras incidimos en esa conflictividad» (Vargas, 2009: 57). Porque en numerosas ocasiones «las mujeres que se comportan de manera menos insegura son aquellas que se sienten que tienen más control de sí mismas y de sus vidas. La confianza está construida, desde luego, sobre los recursos económicos, culturales y sociales, pero también alimentada y reforzada por la habilidad y la disposición de dichas mujeres para correr riesgos, más que para evitarlos» (Pitch, 2008: 5). Y hay mujeres en Lavapiés que deciden asumir riesgos, sobre todo a la hora de volver a casa solas y de noche, de no dejar de realizar actividades políticas o de ocio. El hecho de correr riesgos crea confianza en lugar de disminuirla, lo que no quiere decir que no haya situaciones en las que las mujeres sientan temor. La idea no es conseguir pro- 
tección del exterior, poner cerraduras en la puerta de casa y quedarse dentro, estar a salvo pero en una cárcel. En el debate sobre la seguridad, es importante que las mujeres no sean consideradas como víctimas potenciales que tienen que ser constantemente protegidas, sino como sujetos autónomos.

Yo, en Holanda, estuve estudiando el feminismo de la diferencia [...] y hablaba de que las mujeres no teníamos que ser víctimas, se hablaba de supervivientes [...] porque las mujeres, si tú eres superviviente significa que eres sujeta, o sea que eres un sujeto y que tú tomas decisiones [...] tú eres un agente que cambia también la situación. (V., 40 años)

El derecho a circular sin miedo por las calles a cualquier hora del día y de la noche - como lo hacen los hombres- es una reivindicación constante de muchas mujeres.

Al final, es lo que decían: «La revolución será feminista o no será revolución». Es que, claro, si el patriarcado está ahí perenne, pero, claro, si no lo estamos visibilizando nosotras, al final es estar en pie de guerra y es como «jo, tía, qué pesada eres!». Pero es como « ¿Coño, pero es que me está afectando! Es que yo también quiero ser libre, yo también quiero pasear por las calles y que me dé igual quien venga y quien no venga. No quiero estar escuchando a ver quién viene por detrás, si me cruzo o no me cruzo». (C., 53 años)

Aun así, no se puede concluir que los espacios públicos no sean inseguros para las mujeres. Aunque muchas veces no existe una correspondencia estricta entre las percepciones de inseguridad y los niveles de violencia real, en ocasiones, sí coinciden el temor y una efectiva posibilidad de ser víctima de agresiones. En este sentido, las mujeres que participaron en el grupo de discusión planteaban cómo todas habían sufrido alguna vez un episodio en el que un hombre les había molestado o se había sobrepasado.

Yo siempre lo pienso, un hombre, ¿̇uántos hombres habrán recibido agresiones sexuales? O sea, creo que no hay ni una sola mujer que en algún momento de su vida no se haya sentido mínimamente acosada [...] Vas en el autobús, en el metro, y un tío se te arrima. Eso, ¿̇verdad que nos ha pasado a todas? (V., 40 años)

A las mujeres les corresponde mayoritariamente ser objeto de la mirada (Durán, 2008). Como manifestaban algunas participantes, el marcaje espacial al que ellas se ven sometidas se traduce en una usurpación del derecho a disfrutar de las ventajas del anonimato que deberían presidir las relaciones entre personas desconocidas en espacios públicos. Las mujeres son constantemente víctimas de agresiones expresadas en sus niveles más elementales —el asalto con la mirada, la interpelación grosera en forma de piropo, etc.- - Les desagradan ciertos comportamientos y actitudes que los hombres perciben como inofensivos o aduladores, aunque la mayoría no las consideran una agresión, incluso algunas las consideran un halago. No obstante, les incomoda que los hombres se fijen demasiado en ellas. Se sienten vulnerables ante esta hipervisibilización. 
Como señala Delgado (2007), en la calle, las mujeres pueden descubrir hasta qué punto es cierto lo que aprecia Bourdieu (2000) de que son seres ante todo percibidos, puesto que existen fundamentalmente por y para la mirada de los demás.

En este contexto, las mujeres y sus cuerpos acaban por convertirse en objetos de regulación, de apropiación, de consumo (Tamayo, 2009). Pero el cuerpo también se representa como categoría política:

[...] como ese lugar primero en el cual ejercer los derechos y resistir las violencias: el cuerpo como resistencia. Ese espacio privado y único, el espacio primero del que apropiarnos para poder adueñarnos de otros territorios: la casa, el barrio, la ciudad, el país. El cuerpo de las mujeres como lugar de la defensa de derechos, todavía restringidos, y sobre el cual aún se ejerce el poder y se expresan violencias. Apropiación de los cuerpos, para poder apropiarnos del espacio público. (Falú, 2009: 29)

Según contaba una informante:

La calle es el lugar de apertura, pero también de lo desconocido y representa riesgos. Es importante empoderarse desde el cuerpo. Ese lugar desde el que somos tan visibles como mujeres en el espacio público. (I., 48 años)

\section{Conclusiones}

Como hemos visto, existe una construcción social de los discursos del miedo que puede ser utilizada con diversos fines. Cierta información que aparece en los medios de comunicación y a través de políticas en determinados lugares o sobre determinados colectivos constituyen la base del miedo en el espacio público. En un modelo hegemónico de seguridad donde las estrategias urbanísticas, policiales y del mercado crean todavía mayor inseguridad, la función protectora se ha delegado a instancias formales que, en su origen, no fueron creadas para garantizar protección, sino para imponer disciplina. Esto se ha puesto en evidencia en Lavapiés en relación con el proceso de gentrificación experimentado en el barrio, donde el plan de rehabilitación iniciado en el año 2000 ha querido cambiar no solo el aspecto físico del mismo, sino también el vecinal.

El espacio físico constituye una dimensión activa en las interacciones sociales. Interviene en las formas de uso, en el carácter de las actividades que se desarrollan en él y en la discriminación o en la integración de sus habitantes. No se pueden limitar los lugares de reunión sin propiciar espacios de interlocución, ya que las relaciones cercanas de vecindad contribuyen a aplacar ciertos miedos, sobre todo respecto a esos «otros» encarnados en los inmigrantes. Ya hemos visto cómo el conocimiento del entorno, tanto físico como social, es importante a la hora de superar temores. Una vida en convivencia y no solo de copresencia es uno de los factores que proporciona seguridad.

Se ha señalado que los espacios de sociabilidad e interacción cotidianos tienden a tener definiciones de género, de edad, de clase, que demarcan dominios 
específicos para mujeres y hombres. Sin embargo, tal y como hemos visto, estas definiciones entran en contradicción con la realidad. Las mujeres salen a la calle y participan en diversos espacios de la vida pública, sobrepasando cada vez en más ocasiones las definiciones de dominios específicos y asignaciones espaciales rígidas.

¿Cómo enfrentar de manera efectiva las desigualdades genéricas en la ciudad? La respuesta no ha de excluir las construcciones de poder existentes, así como una incorporación de las distintas dimensiones y de los diversos niveles que conforman la compleja realidad de la vida urbana. Por ello, además de una intervención desde la planificación y el diseño de los espacios municipales, es necesaria una labor que asegure un fortalecimiento de las relaciones vecinales y que tome en cuenta los peculiares rasgos culturales de cada lugar, ya que la participación ciudadana se hace posible en el ámbito local. A través de estas zonas cercanas y accesibles, las mujeres pueden intervenir abriendo las perspectivas de cambio en el ejercicio del poder, desde la apropiación y el control del espacio vecinal, barrial y urbano. Más que hablar de entornos seguros e inseguros, habría que hablar de relaciones seguras o inseguras (Naredo, 2010).

Es interesante, por tanto, que las políticas públicas tengan como prioridad la implicación directa de las mujeres, de manera que se recojan y se expliciten sus necesidades respecto de la (in)seguridad. Es necesario realizar un análisis que permita situarlas como sujetos de la ciudad. Pero la prevención y la educación no han de venir únicamente de la mano de las instituciones o de la capacidad de agencia de las mujeres, es necesaria también la reflexión de los hombres, ya que la relación con la ciudad no es neutra, sino cargada de significado que, como ya se ha señalado, se ha expresado en una dicotomía del mundo urbano que se manifiesta en la dualidad formada por lo público y lo privado. Es necesario producir transformaciones - físicas y simbólicas - en las ciudades que permitan rearticular los ámbitos público y privado, productivo y reproductivo, masculino y femenino, para hacer de los barrios, de las poblaciones, espacios de convivencia ciudadana.

Se trata de crear territorios más igualitarios donde las mujeres puedan ocupar los espacios sin tener que valorar previamente si su manera de actuar, de tomar decisiones, tendrá repercusiones negativas respecto a su seguridad.

\section{Referencias bibliográficas}

Adams, John (1999). «The Risk of Freedom». En: The risk of Freedom: Individual liberty and the modern world [en línea]. Institute of United States Studies. <http:// john-adams.co.uk/wp-content/uploads/2006/risk,\%20freedom\%20\&\%20responsibility.pdf> [Consulta: 2 febrero 2013].

BorJa, Jordi (2003). La ciudad conquistada. Madrid: Alianza.

Bourdieu, Pierre (2000). La dominación masculina. Barcelona: Anagrama.

Cañedo Rodríguez, Montserrat (2011). «Discursos vecinales sobre la inseguridad ciudadana y políticas de rehabilitación urbanística: El caso de los "antiguos vecinos” y la ARI-Lavapiés (Madrid) desde una perspectiva antropológica». Scripta Nova: Revista Electrónica de Geografía y Ciencias Sociales [en línea], 385 (XV), diciembre. Universitat de Barcelona. <http://www.ub.edu/geocrit/sn/sn-385.htm> [Consulta: 26 abril 2013]. 
Durán, María Ángeles (2008). La ciudad compartida: Conocimiento, afecto y uso. Santiago de Chile: Ediciones SUR.

Delgado, Manuel (2007). Sociedades movedizas: Pasos hacia una antropología de las calles. Barcelona: Anagrama.

FALú, Ana (2009). "Violencias y discriminaciones en las ciudades». En: Falú, Ana (ed.). Mujeres en la ciudad: De violencias y derechos. Santiago de Chile: Red Mujer y Hábitat de América Latina. Ediciones SUR, 15-38.

FernÁndez-SAVATER, Amador (2010). «Fuera del lugar: Entrevista a María Naredo». Público [en línea], 23 de enero. <http://blogs.publico.es/fueradelugar/122/si-laciudadania-se-reapropia-de-las-aceras-y-las-calles> [Consulta: 10 marzo 2013].

Machado, Lia Zanotta (2009). «Sin violencia hacia las mujeres: ¿Serían seguras las ciudades para todas y todos?». En: Falú, Ana (ed.). Mujeres en la ciudad: De violencias y derechos. Santiago de Chile: Red Mujer y Hábitat de América Latina. Ediciones SUR, 127-135.

McDowell, Linda (2000). Género, identidad y lugar: Un estudio de las geografías feministas. Madrid: Cátedra.

Michaud, Anne (2006). «Seguridad y convivencia: Un flujo con enfoque de género en el espacio urbano». Urbanisme i gènere, una visió necessària per a tothom. Barcelona: Diputació de Barcelona, 293-301.

Nash, Mary (2007). Mujeres en el mundo: Historia, retos y movimientos. Madrid: Alianza.

PAIN, Rachel (2001). "Gender, race, age and fear in the city». Urban Studies [en línea], 38 (5-6), 899-913. <http://dx.doi.org/10.1080/00420980120046590>

Piтch, Tamar (2008). El género de la seguridad urbana [en línea]. <http://www.ejgv. euskadi.net/r532291/es/contenidos/informacion/sare2007/es_berdingu/adjuntos/ pitch.t_07_cast.pdf> [Consulta: 29 diciembre 2012].

RaINero, Liliana (2009). «Ciudad, espacio público e inseguridad: Aportes para el debate desde una perspectiva feminista». En: Falú, Ana (ed.). Mujeres en la ciudad: De violencias y derechos. Santiago de Chile: Red Mujer y Hábitat de América Latina. Ediciones SUR, 163-176.

Román Rivas, Marta (2009). «Recuperar la confianza, recuperar la ciudad». En: FALú, Ana (ed.). Mujeres en la ciudad: De violencias y derechos. Santiago de Chile: Red Mujer y Hábitat de América Latina. Ediciones SUR, 137-144.

Segura Soriano, Isabel (2006). "La memoria, una forma de arquitectura». Urbanisme i gènere, una visió necessària per a tothom. Barcelona: Diputació de Barcelona, 195-198.

Tamayo, Giulia (2009). «Debates abiertos en materia de seguridad desde los derechos humanos de las mujeres». En: Falú, Ana (ed.). Mujeres en la ciudad: De violencias y derechos. Santiago de Chile: Red Mujer y Hábitat de América Latina. Ediciones SUR, 39-54.

VAlle, Teresa del (1997). Andamios para una nueva ciudad: Lecturas desde la antropología. Madrid: Cátedra.

- (2006). "Seguridad y convivencia: Hacia nuevas formas de transitar y habitar». Urbanisme i gènere, una visió necessària per a tothom. Barcelona: Diputació de Barcelona, 275-292.

VARGAS, Virginia (2009). «La violencia de género: pistas para un análisis». En: Falú, Ana (ed.). Mujeres en la ciudad: De violencias y derechos. Santiago de Chile: Red Mujer y Hábitat de América Latina. Ediciones SUR, 55-60. 


\section{Anexos}

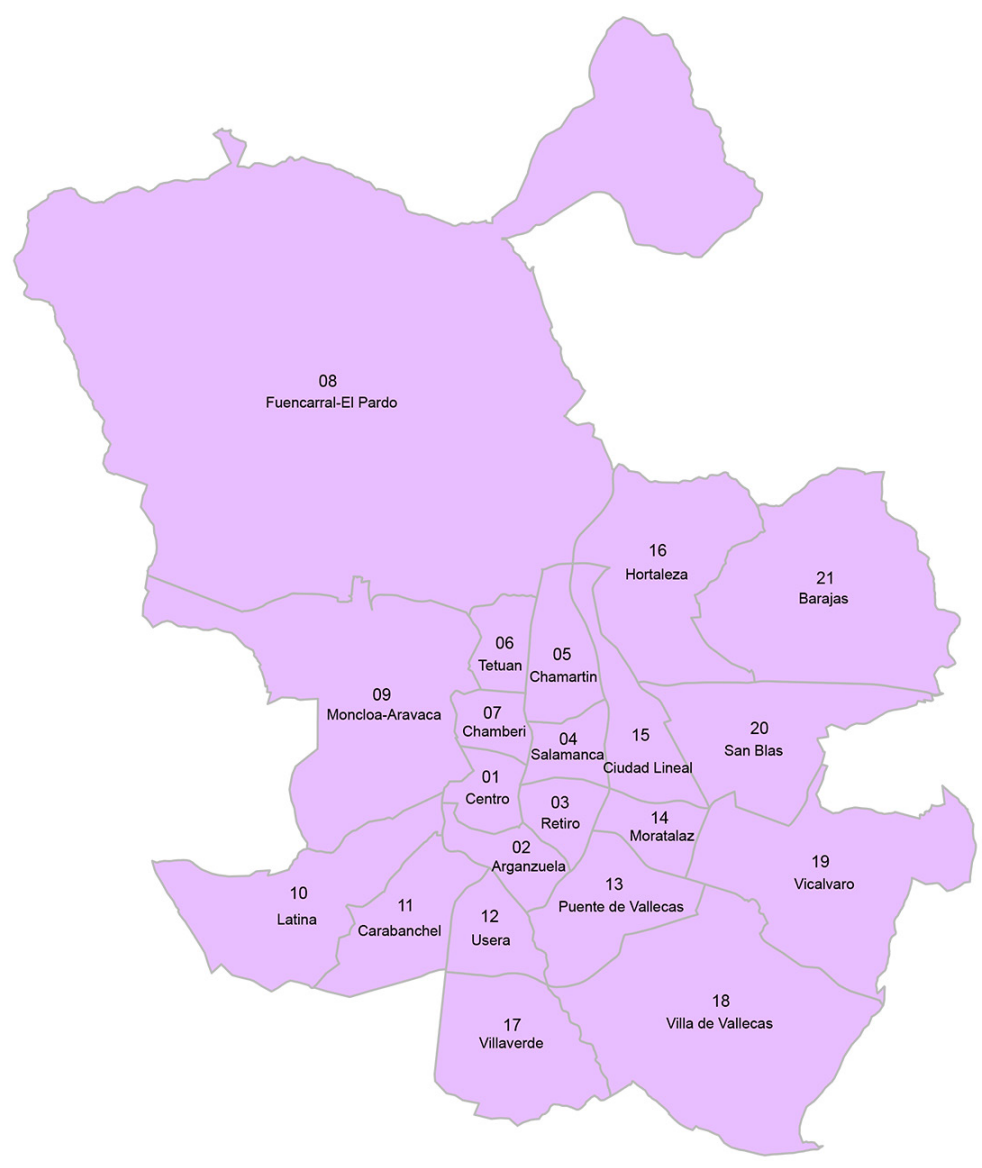

Figura 1 anexo. Plano esquemático de Madrid con ubicación del distrito Centro (01), al que corresponde el barrio de Embajadores.

Fuente: Dirección General de Estadística del Ayuntamiento de Madrid. 

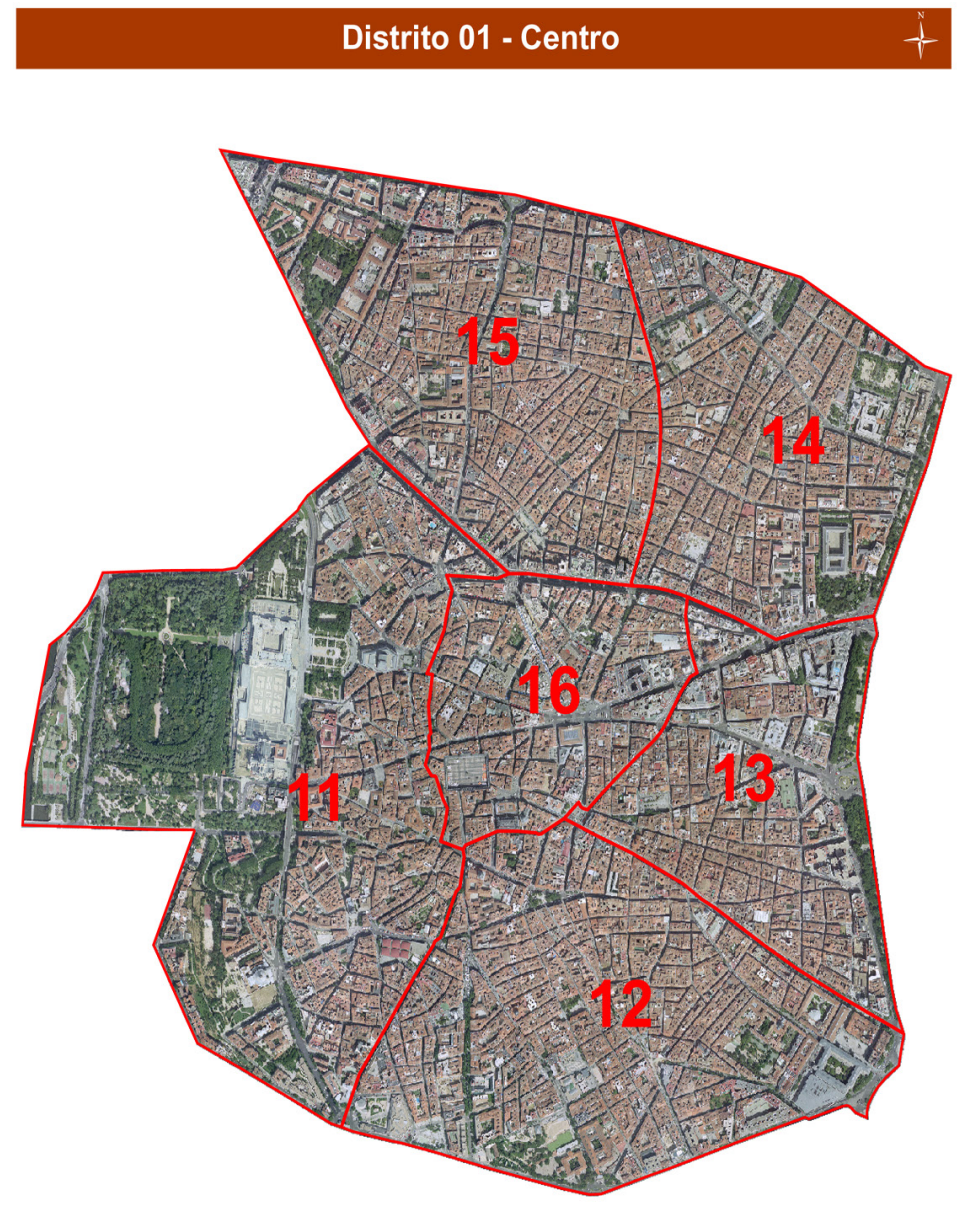

\begin{tabular}{|l|}
\hline Barrios \\
11 - Palacio \\
12 - Embajadores \\
13 - Cortes \\
14 - Justicia \\
15 - Universidad \\
16 - Sol \\
\hline
\end{tabular}

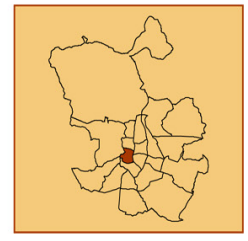

Figura 2 anexo. Imagen satélite del distrito Centro de Madrid, con ubicación esquemática de sus barrios. El barrio de Embajadores, al que corresponde Lavapiés, está señalado como 12. Fuente: Dirección General de Estadística del Ayuntamiento de Madrid. 


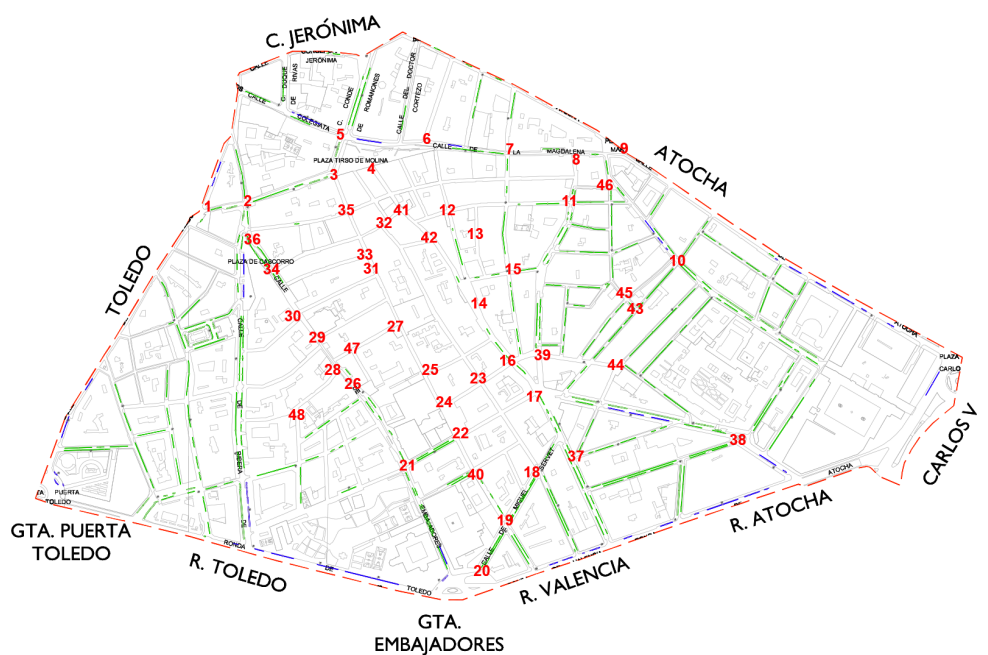

1 Plaza de la Cebada / Toledo

2 Duque de Alba / Estudio

3 Plaza de Tirso de Molina /Mesón de Paredes

4 Plaza de Tirso de Molina / Jesús y María

5 Plaza de Tirso de Molina / Colegiata

6 Magdalena / Relatores

7 Magdalena / Cañizares

8 Magdalena / Ave María

9 Atocha / León

10 Santa Isabel / San Cosme y San Damián

11 Olmo / Ave María

12 Lavapiés / Calvario

13 Ministriles, 16

14 Lavapiés, 40

15 Olivar / San Carlos

16 Plaza de Lavapiés / Sombrerete

17 Valencia / Tribulete

18 Miguel Servet / Amparo

19 Miguel Servet / Mesón de Paredes

20 Miguel Servet / Glorieta de Embajadores

21 Embajadores/Tribulete

22 Tribulete / Mesón de Paredes

23 Sombrerete / Amparo

24 Mesón de Paredes / Sombrerete
25 Mesón de Paredes / Caravaca

26 Embajadores, 46

27 Mesón de Paredes / Cabestreros

28 Embajadores/Rodas

29 Embajadores, 24-26

30 Embajadores/San Cayetano

31 Mesón de Paredes, 23-25

32 Amparo/Esgrima

33 Mesón de Paredes / Dos Hermanas

34 Embajadores/Encomienda

35 Mesón de Paredes / Juanelo

36 Plaza del Cascorro / Embajadores

37 Valencia / Sombrerería

38 Argumosa/Dr. Fourquet

39 La Fe / Plaza de Lavapiés

40 Mesón de Paredes / Provisiones

41 Jesús y María / Calvario

42 Jesús y María / Travesía de la Comadre

43 Zurita / Torrecilla del Leal

$44 \mathrm{La} \mathrm{Fe} /$ Salitre

45 Torrecilla del Leal / Buenavista

46 Rosa / Santa Isabel

47 Cabestreros / Travesía de los Cabestreros

48 Rodas / Peña de Francia

Figura 3 anexo. Plano de Lavapiés con la situación de las cámaras de videovigilancia. Fuente: Dirección General de Sostenibilidad y Control Ambiental del Ayuntamiento de Madrid. 
Tabla 1 anexo. Perfil de las mujeres participantes mediante entrevista

\begin{tabular}{|c|c|c|c|c|c|c|}
\hline Nombre $^{1}$ & Edad & Nivel de estudios & $\begin{array}{l}\text { Residente } \\
\text { en Lavapiés }\end{array}$ & Ocupación & Origen & Modo de contacto \\
\hline Aida & 34 & Titulación superior & No & Desempleada & España & $\begin{array}{l}\text { Contacto personal en el taller «Herramientas } \\
\text { para la búsqueda de emple0»²}\end{array}$ \\
\hline Carmen & 43 & Titulación superior & No & Investigadora & España & $\begin{array}{l}\text { Contacto personal mediante el grupo } \\
\text { de consumo }\end{array}$ \\
\hline Conchi & 53 & Titulación media & Sí & $\begin{array}{l}\text { Socia de un bar } \\
\text { y camarera }\end{array}$ & España & Contacto personal en el bar donde trabaja \\
\hline Dora & 49 & Titulación media & $\begin{array}{l}\text { No en la } \\
\text { actualidad }^{4}\end{array}$ & Desempleada & Alemania & Personal $^{5}$ \\
\hline Ester & 52 & BUP & No & $\begin{array}{l}\text { Socia de un bar } \\
\text { y camarera }\end{array}$ & España & $\begin{array}{l}\text { Contacto personal mediante el grupo } \\
\text { de consumo }\end{array}$ \\
\hline Eva & 42 & Titulación superior & No-B012 ${ }^{6}$ & $\begin{array}{l}\text { Funcionaria de } \\
\text { Hacienda }\end{array}$ & España & Personal \\
\hline Gala & 53 & Bachiller superior & No & Desempleada & España & $\begin{array}{l}\text { Contacto personal en el taller «Herramientas } \\
\text { para la búsqueda de empleo» }\end{array}$ \\
\hline Irene & 48 & Titulación superior & No & $\begin{array}{l}\text { Coacher de } \\
\text { empoderamiento }\end{array}$ & España & $\begin{array}{l}\text { Contacto personal en el taller «Herramientas } \\
\text { para la búsqueda de empleo» }\end{array}$ \\
\hline Iria & 39 & $\begin{array}{l}\text { Titulación media. } \\
\text { Estudios superiores } \\
\text { de Arte Dramático }\end{array}$ & No-B012 & $\begin{array}{l}\text { Actriz y } \\
\text { recepcionista }\end{array}$ & España & Por terceras personas ${ }^{7}$ \\
\hline Isabel & 28 & Diplomatura & Sí & Desempleada & España & Contacto personal en La Tabacalera \\
\hline Luisa & 33 & Titulación superior & Sí & Administrativa & España & $\begin{array}{l}\text { Contacto personal en el taller «Herramientas } \\
\text { para la búsqueda de empleo» }\end{array}$ \\
\hline Loreto & 41 & Titulación superior & $\begin{array}{l}\text { No en la } \\
\text { actualidad }\end{array}$ & Funcionaria & España & Personal \\
\hline Nerea & 25 & Titulación media & No & Desempleada & España & $\begin{array}{l}\text { Contacto personal en el taller «Herramientas } \\
\text { para la búsqueda de empleo» }\end{array}$ \\
\hline Paola & 47 & Titulación superior & Sí & Desempleada & España & $\begin{array}{l}\text { Contacto personal en el taller «Herramientas } \\
\text { para la búsqueda de empleo» }\end{array}$ \\
\hline Rocío & 39 & Titulación superior & No & Auditora y analista & España & Personal \\
\hline Viola & 40 & Titulación superior & $\begin{array}{l}\text { No en la } \\
\text { actualidad(4) }\end{array}$ & Escritora y poetisa & España & Por terceras personas \\
\hline
\end{tabular}

1. Siguiendo con la idea de mantener el anonimato de las mujeres participantes en el estudio, los nombres que aparecen en la tabla son ficticios.

2. Taller «Herramientas para la búsqueda de empleo», organizado por el Consejo de las Mujeres del Municipio de Madrid.

3. Grupo de consumo de La Tabacalera, creado para comprar directamente productos agrícolas sin personas intermediarias.

4. Han vivido en el barrio, pero en la actualidad no residen en él.

5. Ya existía un conocimiento con la informante previo al trabajo de campo.

6. Residente en el barrio de Embajadores, pero no en la zona de Lavapiés.

7. Estas informantes han sido introducidas por otras mujeres a las que ya se había entrevistado. 
Tabla 2 anexo. Perfil de las mujeres participantes mediante conversaciones informales

\begin{tabular}{|c|c|c|c|c|c|c|}
\hline Nombre $^{1}$ & Edad & Nivel de estudios & $\begin{array}{l}\text { Residente en } \\
\text { Lavapiés }\end{array}$ & Ocupación & Origen & Modo de contacto \\
\hline Adela & 49 & BUP & No & Desempleada & España & $\begin{array}{l}\text { Contacto personal en el taller «Herramientas } \\
\text { para la búsqueda de empleo» }\end{array}$ \\
\hline Amina & 29 & Enseñanza primaria & Sí & $\begin{array}{l}\text { Empleada en } \\
\text { un locutorio }\end{array}$ & Marruecos & Contacto personal en locutorio \\
\hline Carmen & 83 & $\begin{array}{l}\text { Enseñanza primaria } \\
\text { incompleta }\end{array}$ & Sí & Ama de casa & España & Contacto personal en la calle \\
\hline Dhurjati & 27 & $\mathrm{Ns} / \mathrm{Nc}^{2}$ & Sí & $\begin{array}{l}\text { Empleada en } \\
\text { un locutorio }\end{array}$ & Bangladés & Contacto personal en locutorio \\
\hline Fátima & 27 & Enseñanza primaria & Sí & Ama de casa & Marruecos & Contacto personal en locutorio \\
\hline $\mathrm{Li}$ & 22 & $\begin{array}{l}\text { Enseñanza primaria } \\
\text { incompleta }\end{array}$ & No & Esteticista & China & Contacto personal en centro cosmético \\
\hline María & 30 & Diplomatura & Sí & Desempleada & Ecuador & $\begin{array}{l}\text { Contacto personal en el parque del Casino } \\
\text { de la Reina }\end{array}$ \\
\hline Martha & 29 & $\begin{array}{l}\text { Formación } \\
\text { profesional de } \\
\text { segundo grado }\end{array}$ & Sí & $\begin{array}{l}\text { Cuidadora } \\
\text { de un anciano }\end{array}$ & Colombia & Contacto personal en la calle \\
\hline Merche & 53 & $\begin{array}{l}\text { Enseñanza primaria } \\
\text { incompleta }\end{array}$ & Sí & Ama de casa & España & Contacto personal en la calle \\
\hline Pepa & 60 & Titulación media & Sí & Jubilada & España & Contacto personal en la calle \\
\hline Petra & 78 & Bachiller elemental & Sí & Jubilada & España & Contacto personal en la calle \\
\hline Wei & 38 & $\mathrm{Ns} / \mathrm{Nc}$ & No & $\begin{array}{l}\text { Empleada en un } \\
\text { establecimiento }\end{array}$ & China & $\begin{array}{l}\text { Contacto personal en comercio de venta } \\
\text { al por mayor }\end{array}$ \\
\hline Xiaomei & 40 & $\mathrm{Ns} / \mathrm{Nc}$ & Sí & $\begin{array}{l}\text { Empleada en un } \\
\text { establecimiento }\end{array}$ & China & Contacto personal en tienda de comestibles \\
\hline Ying & 19 & ESO & Sí & $\begin{array}{l}\text { Empleada en un } \\
\text { establecimiento }\end{array}$ & China & Contacto personal en tienda de comestibles \\
\hline
\end{tabular}

1. Al igual que en la tabla anterior, los nombres que aparecen son ficticios.

2. No sabe / No contesta. 